\title{
РОССИЙСКИЙ РЫНОК КОРПОРАТИВНЫХ ОБЛИГАЦИЙ: ПРОБЛЕМЫ И ПЕРСПЕКТИВЫ РАЗВИТИЯ В СОВРЕМЕННЫХ УСЛОВИЯХ
}

\author{
(c) 2018 Паршин Максим Александрович \\ Финансовый университет при Правительстве Российской Федерации \\ 125993, г. Москва, Ленинградский пр-т, д. 49 \\ E-mail:pmaxcv@gmail.com
}

Целью работы является исследование перспектив развития рынка корпоративных облигаций. В статье выявлены основные проблемы, препятствующие развитию рынка корпоративных облигаций. Одной из основных проблем является ограничение спроса со стороны инвесторов. При проведении детального анализа выявлены факторы, влияющие на ограничение спроса на рынке корпоративных облигаций. В результате работы проанализированы основные факторы, способствующие развитию данного рынка.

Ключевые слова: ценные бумаги; корпоративные облигации; инвесторы; рынок корпоративных облигаций.

Президент Российской Федерации В. Путин в ежегодном Послании Федеральному Собранию (01.12.2016 года) обозначил значимость развития финансового рынка, совершенствование которого позволяет привлекать средства инвесторов и граждан в экономику через облигации и другие механизмы. Современные ученые в научных трудах также придают большое значение развитию рынка корпоративных облигаций [1; $1-317]$.

Необходимость развития финансового рынка, а именно, в качестве развития рынка корпоративных облигаций вызвана несколькими факторами.

Корпоративные облигации являются как альтернативным, так дополнительным банковскому кредитованию внешним источником финансирования предприятий. Известно, что предприятия, в период своего развития, нуждаются в заемных средствах, которые необходимы для покрытия долгосрочных производственных и капитальных затрат, направленных на расширение бизнеса, создания новых видов продукции, внедрение инноваций и выхода на новые рынки. Зачастую, предприятия сталкиваются с ситуациями, когда в связи с дефицитом залоговой массы, банки отказываются кредитовать или кредитуют в объеме, недостаточном для решения поставленных задач. Таким образом, предприятия подвергаются негативному «эффекту упущенных возможностей», который можно избежать путем выпуска корпоративных облигаций.

При финансировании с помощью эмиссии корпоративных облигаций, у заемщика возникает ряд преимуществ:

- Широкая база инвесторов.

- Отсутствие залогового обеспечения.

- Длительный срок заимствования.

- Публичная кредитная история (позволяет снижать стоимость дальнейшего заимствования).

- Возможность налаживания отношений с инвесторами по другим вопросам, в т.ч. в области акционерного капитала.

- Повышение узнаваемости брэнда.

В последние десятилетия, в развитых странах происходит увеличение значимости рынка корпоративных облигаций, повышается интерес со стороны федеральных и региональных органов государственной власти.

Крупные предприятия, используя в качестве основного источника внешнего финансирования эмиссию корпоративных облигаций, освобождают средства кредитных организаций, которые, за счет смягчения условий банковского кредитования и повышения лояльности к клиентам, смогут направить данные средства на кредитование субъектов экономики, не имеющим доступа к облигационным займам, например, предприятий малого бизнеса. Таким образом, увеличится объем средств, поступающих в развитие национальной и региональной экономики.

Кроме того заимствования с помощью корпоративных облигаций, за счет широкой базы инвесторов, позволяют привлекать дополнительные инвестиции в регионы. Это наблюдает- 
ся при реализации региональными предприятиями долгосрочных инвестиционных проектов, финансирование которых осуществляется путем эмиссии корпоративных облигаций. Таким образом, происходит развитие субъектов РФ за счет привлечения денежных средств без участия регионального бюджета.

\section{Проблемы}

При размещении корпоративных облигаций потенциальные эмитенты сталкиваются с определенными проблемами, которые препятствуют успешной регистрации выпуска. Одной из основных проблем успешного размещения является отсутствие спроса на бумаги со стороны инвесторов. По приемлемым процентным ставкам на рынке корпоративных облигаций могут занимать уже зрелые и надежные компании, которые имеют опыт эмиссии и успешного погашения выпусков. Таким образом, для привлечения инвесторов эмитентам-дебютантам необходимо увеличить доходность по размещаемым облигациям, которая должна превышать доходность по облигациям зрелых предприятий и, соответственно, быть выше депозитной доходности.

Кроме того, потенциальный эмитент должен обладать следующими характеристиками, определенными профессиональным сообществом: наличие за последние три года аудированной отчетности по МСФО, умеренная долговая нагрузка (соотношение Чистый Долг/EBITDA не более 3), годовой объем выручки должен превышать 2 млрд. рублей, прозрачная бизнес-модель и юридическая структура, а также желательно наличие кредитного рейтинга [4].

Изменения в законодательстве также способствуют ограничению спроса на корпоративные облигации со стороны потенциальных инвесторов. Согласно Проекту Постановления Правительства РФ от 30.05.2017 государственные компании и корпорации с 14.07.2017 года могут инвестировать свободные денежные средства в ценные бумаги эмитентов, получивших рейтинг рейтингового агентства Аналитическое кредитное рейтинговое агентство АКРА не ниже BВB- (умеренный уровень кредитоспособности). Данное изменение в законодательстве ограничит количество инвесторов, так как процедура присвоения рейтинга, за счет высокой стоимости, для многих потенциальных эмитентов не доступна.

Еще одним препятствием успешного размещения корпоративных облигаций является низкий уровень биржевого листинга (на уровень листинга влияют объем выпуска, представление проспекта биржевых об срок существования эмитента (поручителя гаранта), раскрытие информации отсутствие убытков отсутствие дефолтов наличие определенного кредитного рейтинга, наличие обеспечения). От уровня листинга напрямую зависит уровень доверия инвесторов к предприятию и выпуску, что в дальнейшем может отразиться на спросе.

Рынок ценных бумаг не стоит на месте, происходит непрерывное его развитие, появляются финансовые инструменты, адаптированные на текущую ситуацию в экономике. За период 2016-2017 года появились новые «конкуренты» корпоративных облигаций: купонные облигации Банка России (КОБР), облигации для народа, выпускаемые Минфином РФ (ОФЗ-н), а также облигации для населения, размещаемые кредитными организациями.

В августе 2017 года Банк России решил абсорбировать ликвидность путем эмиссии купонных облигаций, размещение которых происходит только среди кредитных организаций. По данным официального сайта Московской биржи, торговый оборот кредитных организаций на рынке корпоративных облигаций составляет порядка 70 процентов от общего оборота. Таким образом, происходит перераспределение средств потенциальных инвесторов в сторону КОБР.

Еще одним фактором, ограничивающим спрос на корпоративные облигации, являются облигации для народа (ОФЗ-н). Это ценные бумаги, выпускаемые Минфином специально для распространения среди населения: их проще приобрести, чем рыночные облигации, и риски ограничены, так как государство является гарантом возврата инвестиций. Размещая ОФЗ-н, государство по фиксированной процентной ставке заимствует денежные средства населения. При минимальном уровне риска, доходность от инвестирования средств в данный инструмент выше, чем средняя доходность по вкладам.

Успешное размещение Минфина является предпосылкой возникновения еще одного финансового инструмента - облигаций для населения, размещаемых кредитными организациями (ВТБ 24 (ПАО), АО «Россельхозбанк», ПАО Сбербанк), которые планируют начать размещение осенью 2017 года. Размещение облигаций для населения позволит отвлечь часть средств 
населения, которую оно могло бы инвестировать в корпоративные облигации.

\section{Перспективы}

В настоящее время российский банковский сектор находится в состоянии профицита ликвидности, то есть в устойчивой потребности в размещении свободных средств кредитных организаций. Распределение ликвидности в банковском секторе носит неоднородный характер - у большинства банков избыток ликвидности, у остальных ее недостаток. Таким образом, у кредитных организаций появляется возможность инвестировать свои свободные денежные средства. На межбанковском денежном рынке, в условиях профицита ликвидности, достаточно сложно найти партнера для размещения своих средств, поэтому банки участвуют в депозитных аукционах, доходность которых находится на одном уровне со средней доходностью корпоративных облигаций, но предложение депозитных аукционов ограничено, и перед банками встает выбор между государственными и корпоративными ценными бумагами. Государственные бумаги менее рискованные, но и доходность по ним значительно ниже корпоративных (за период с начала 2016 года по июль 2017 разница в доходности в среднем составляет $1,5 \%)$. Таким образом, кредитные организации, в целях получения повышенного дохода, имеют возможность инвестировать средства в корпо- ративные облигации. На рисунке 1 можно более подробно наблюдать динамику доходностей по различным инструментам инвестирования.

Кроме кредитных организаций инвесторами могут выступать физические и юридические лица. Доходность корпоративных облигаций значительно выше доходности по депозитам. С учетом того, что процентные ставки следуют за ключевой ставкой, розничные инвесторы, для получения наибольшего дохода, вынуждены выбирать более привлекательные, хоть и более рисковые источники инвестирования. Новички рынка корпоративных облигаций могут инвестировать в облигации первого эшелона, в то время как более опытных инвесторов могут заинтересовать облигации, находящиеся во втором и третьем уровнях листинга, с повышенным уровнем дохода и риска.

Для исследования потенциала роста рынка корпоративных облигаций разделим денежные средства розничных инвесторов и выделим ту часть, которая может быть инвестирована на рынке корпоративных облигаций. Потенциальные инвестиции можно разделить на три части: депозиты юридических лиц, вклады физический лиц, а также сбережения населения («средства под подушкой»).

Объем средств физических и юридических лиц на депозитных счетах непрерывно увеличивается. В среднем ежегодный прирост де-

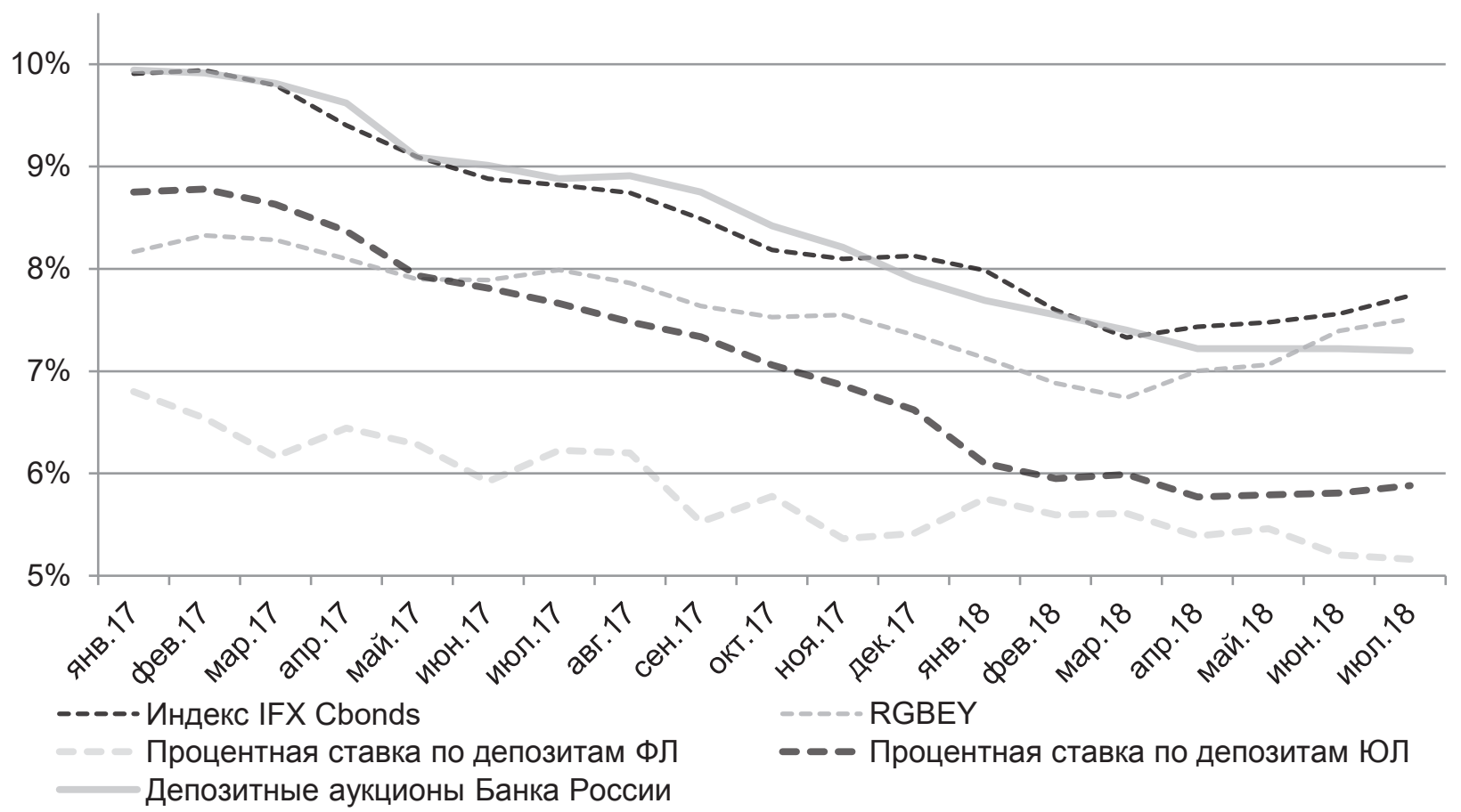

Puc. 1. Динамика доходности депозитов, государственных и корпоративных облигаций 


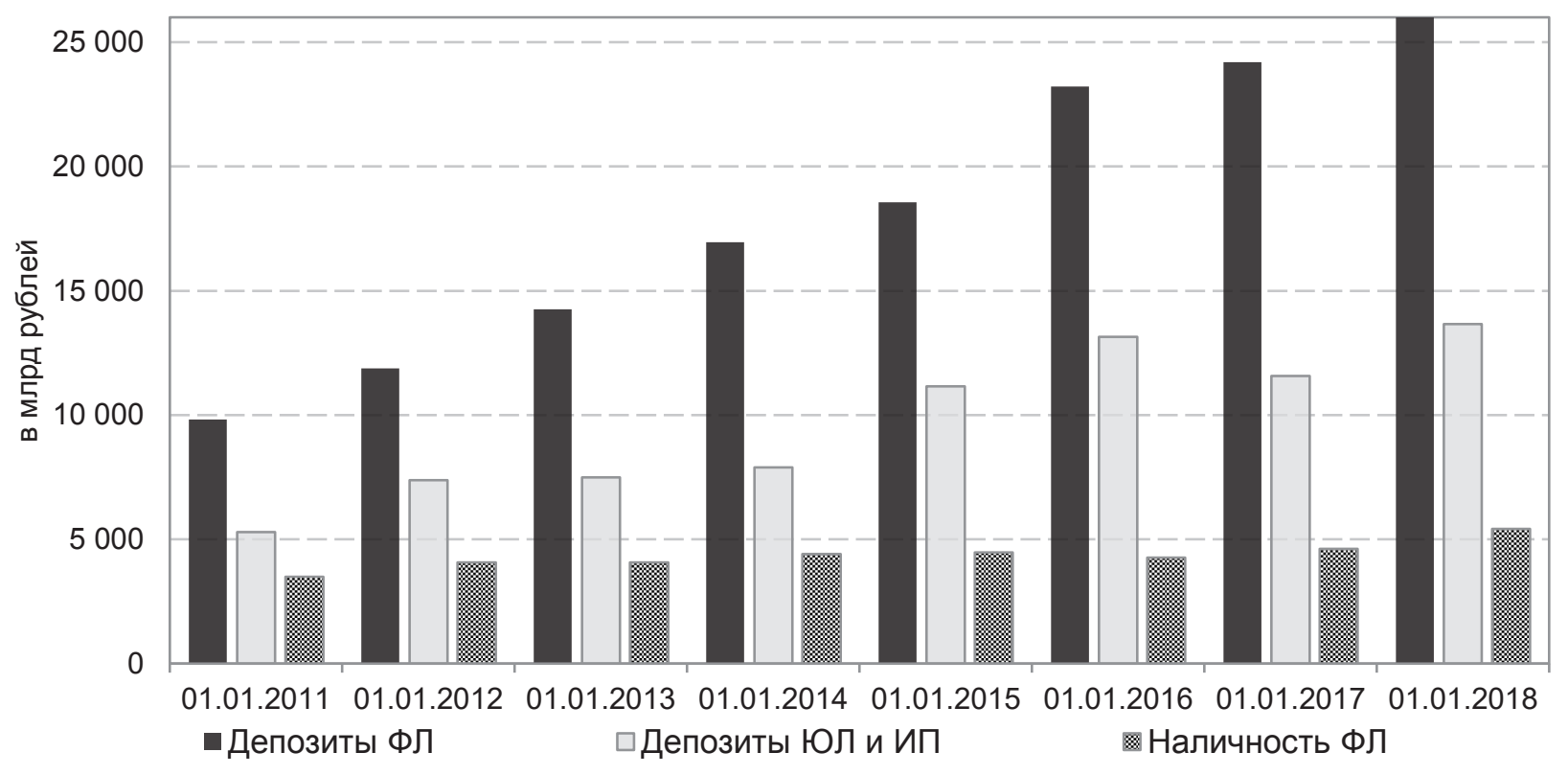

Puc. 2. Динамика потенциально возможных для инвестирования денежных средств

позитных средств составляет $16 \%$. При создании определенных условий (снижение рисков, увеличение доходности) депозитные средства могут быть направлены на рынок корпоративных облигаций. Кроме того, население хранит денежные средства в виде наличности, объем которой практически не изменяется (4 трлн. рублей), но данные средства не рассматриваются, как потенциальные инвестиции.

Также, мерой для ограничения рисков, обретения успешной истории и надежности, эмитенты, в качестве дебютного выпуска, могут разместить корпоративные облигации на более короткий срок. Так, например, 25 августа 2017 года был зарегистрирован пилотный выпуск исламских облигаций, сроком обращения -62 дня. Таким образом, эмитенты смогут обрести успешную историю заимствований на рынке корпоративных облигаций (в случае полного и своевременного погашения основного долга и дохода), а также заработать репутацию надежного и платежеспособного заемщика. Таким образом, новый, для российского фондового рынка, финансовый инструмент в будущем может обрести популярность и расширенное использование.

При популяризации рынка корпоративных облигаций роль государственного воздействия носит неотъемлемый характер. В настоящее время, на утверждении находится законопроект, упрощающий процедуру регистрации корпора- тивных облигаций, а также сокращающий срок между принятием эмитентом решения о выпуске облигаций и их размещением.

Ко всему прочему, Банк России, Минфин и Минэкономразвития обсуждают оказание поддержки (в виде субсидирования процентных ставок) предприятиям-эмитентам из регионов при размещении корпоративных облигаций. Государственная поддержка позволит региональным эмитентам, не имеющим опыта в привлечении облигационных займов, выйти на рынок корпоративных облигаций, а опытным эмитентам привлекать заемные средства по более выгодным условиям.

Для привлечения средств физических лиц на рынок ценных бумаг, Государственной думой РФ рассматривается вопрос о страховании средств населения, находящихся на индивидуальных инвестиционных счетах. Принятие данного законопроекта позволит уменьшить риски населения.

\section{Заключение}

В текущих рыночных условиях потенциал увеличения объемов эмиссии корпоративных облигаций имеет место быть. Государство смягчает требования к регистрации выпусков, сокращает срок рассмотрения документов. Значительное влияние на рост облигационного рынка окажет государственная поддержка в виде субсидирования процентных ставок. Страхование денежных средств на ИИС позволит снизить 
риски розничных инвесторов. В таких услови- облигаций. Появляются конкурентные финанях население, в поисках большей доходности, совые инструменты: КОБРы, ОФЗ-н, облигации перенаправит часть депозитных средств на для народа, эмитируемые кредитными органиИИС, и в дальнейшем сможет инвестироваться зациями. Государство ужесточает требования данные средства в корпоративные облигации. к выпускам, включенным в Ломбардный список Однако существуют факторы, негативно сказы- Банка России, к инвестиционным портфелям говающиеся на развитии рынка корпоративных скомпаний и госкорпораций.

\section{Библиографический список}

1. Актуальные вопросы развития рынка облигаций (по материалам совещания в Уфе) // Деньги и кредит. 2017. № 3. С. 70-71;

2. Минфин России: облигации для населения призваны восстановить доверие граждан к государству // Деньги и кредит. 2017. № 4. С. 80;

3. Облигационный рынок: анализ тенденций и перспектив: монография / под науч. ред. Т.В. Тепловой.- М.: «ИНФРА-М», 2016,- 317 с.- (Научная мысль);

4. Официальный сайт Банка России [Электронный ресурc]: URL: https://www.cbr.ru/ (дата обращения: 23.07.2018);

5. Официальный сайт Группы компаний Cbonds [Электронный ресурc]: URL: http://www.cbonds.ru/ (дата обращения: 10.07.2018);

6. Официальный сайт ПАО Московская биржа [Электронный ресурc]: URL: http://www.moex.com/a1186 (дата обращения: 22.07.2018);

7. Официальный сайт Президента России [Электронный ресурс]: URL: http://kremlin.ru/events/president/ news/53379 (дата обращения: 18.07.2018). 